\title{
Relation of Menarche, and Breast and Ovarian Cancer in Women
}

\author{
Sunanda Bareppady ${ }^{1}$ Sabitha Nayak ${ }^{1}$ \\ ${ }^{1}$ Department of OBG Nursing, Nitte Usha Institute of Nursing \\ Sciences, NITTE (Deemed to be University) Mangaluru, Mangaluru, \\ India
}

J Health Allied Sci ${ }^{\text {NU }}$ 2019;9:76-80

\begin{abstract}
Address for correspondence Sunanda Bareppady, MSc Nursing, Department of OBG Nursing, Nitte Usha Institute of Nursing Sciences, NITTE (Deemed to be University) Mangaluru,Mangaluru, India (e-mail: sunanda@nitte.edu.in).
\end{abstract}

Abstract

Keywords

- menarche

- breast cancer

- ovarian cancer
Cancer is one of the leading causes of death in India and it has become an important public health problem, with more than 800,000 new cases being reported every year. In India, the most frequent cancers usually seen among women are those of cervix, uterus, breast, ovary, lip, oral cavity, and esophagus. Among these, breast and ovarian cancer are seen frequently in Indian women. The study is aimed at finding the relationship of menarche with breast and ovarian cancer, and also determining the association between types of cancer and selected demographic variables. A descriptive study was conducted on a sample consisting of 100 participants at the Justice K.S Hegde Charitable Hospital, Mangaluru. The result showed that majority (56\%) of the sample experienced their first menarche at less than 13 years and had no family history of breast or ovarian cancer. Among the 100 women, $62 \%$ were diagnosed with breast cancer. There is a significant association between types of cancer and age. The $p$-value is 0.027 at $(p<0.05)$ level of significance. The study concluded that there is a significant association between types of cancer with age.

\section{Introduction}

Cancer is perhaps the cruelest of deadly diseases in the current era. Many factors play an important role in cancer and theses features were characterized in 2011 as belonging to the following eight categories: Evasion of apoptosis, excessive growth signaling, insensitivity to growth signals, maintained angiogenesis, endless replicative potential, metastasis, reprogramming of energy metabolism, and avoidance of immune destruction. Types of cancer may be placed in different categories (or combinations of these) according to the symptoms and pathogenesis, thereby revealing multiple relationships. ${ }^{1}$

Breast cancer is always caused by a genetic abnormality (a "mistake" in the genetic material). However, only 5 to $10 \%$ of cancers are caused due to an abnormality inherited from the mother or father. Instead, 85 to $90 \%$ of breast cancers are caused due to genetic abnormalities that occur as a result of the aging process and the "wear and tear" of life in general. ${ }^{2}$

According to 2018 statistics, it is estimated that approximately 22,240 new cases of ovarian cancer will be diagnosed and 14,070 ovarian cancer deaths will occur in the United States. ${ }^{3}$ In India, 1,62,468 new breast cancer cases were registered as per 2018 statistics, out of which 87,090 patients died. The incidence rates in India begin to rise in the early thirties and peak between the ages of 50 and 64 years. Overall, 1 in 28 women are likely to develop breast cancer during their lifetime. In urban areas, 1 in 22 women are likely to develop breast cancer during their lifetime as compared with rural areas where 1 in 60 women develop breast cancer in their lifetime. ${ }^{4}$

A prospective observational study was conducted on breast cancer in Kerala among 180 patients. The results found that the majority of cases were between the age group of 51 to 60 years, in that most of the patients were postmenopausal and married. The majority of the patients resided in urban area, and there existed no family history of cancer. Fifty-one participants experienced their first menarche at the age of 14 years. $^{5}$

Early onset of menarche has been the risk factor contributing to breast cancer, ovarian cancer, and other diseases by increasing received

July 1, 2019

accepted after revision

September 19, 2019
Copyright $\odot 2019$ Nitte University (Deemed to be University)
License terms

(우 (1) $\ominus \circledast$ 
life time exposure to estrogen. It is mentioned that age at menarche is one of the strong causes for breast cancer risk. It is estimated that there is a 5 to $15 \%$ decrease in risk for the development of breast cancer later in life for each year of menarcheal delay. The etiology of ovarian cancer is not well understood, but studies suggest that the suppression of ovulation during the child bearing years-through pregnancy, lactation, oral contraceptives-reduces women's risk of contracting it. ${ }^{6}$

This shows the importance of hormone-dependent cases of breast and ovarian cancer which can be prevented by modifiable lifestyle and environmental factors. Nurses need to provide current and accurate information concerning the latest approaches to breast cancer treatment and related complications. The clients and their families are required to make many difficult decisions. The nurse can be especially helpful by ensuring that the client understands appropriate treatment modalities and options. $^{7}$

\section{Materials and Methods}

A descriptive research design was adopted for the present study. The purpose of this design was to find the relationship of age at menarche of women who have diagnosed with breast and ovarian cancer. Age at menarche was found by demographic Performa. The aim of the study to find the relationship of early menarche with breast and ovarian cancer and to find the association between types of cancer and selected demographic variables. The demographic variables in this study are age in years, occupation, educational status, age at menarche, area of residence, family history of breast or ovarian cancer, gestational age at birth, birth weight, BMI. The research variable refers to relationship of

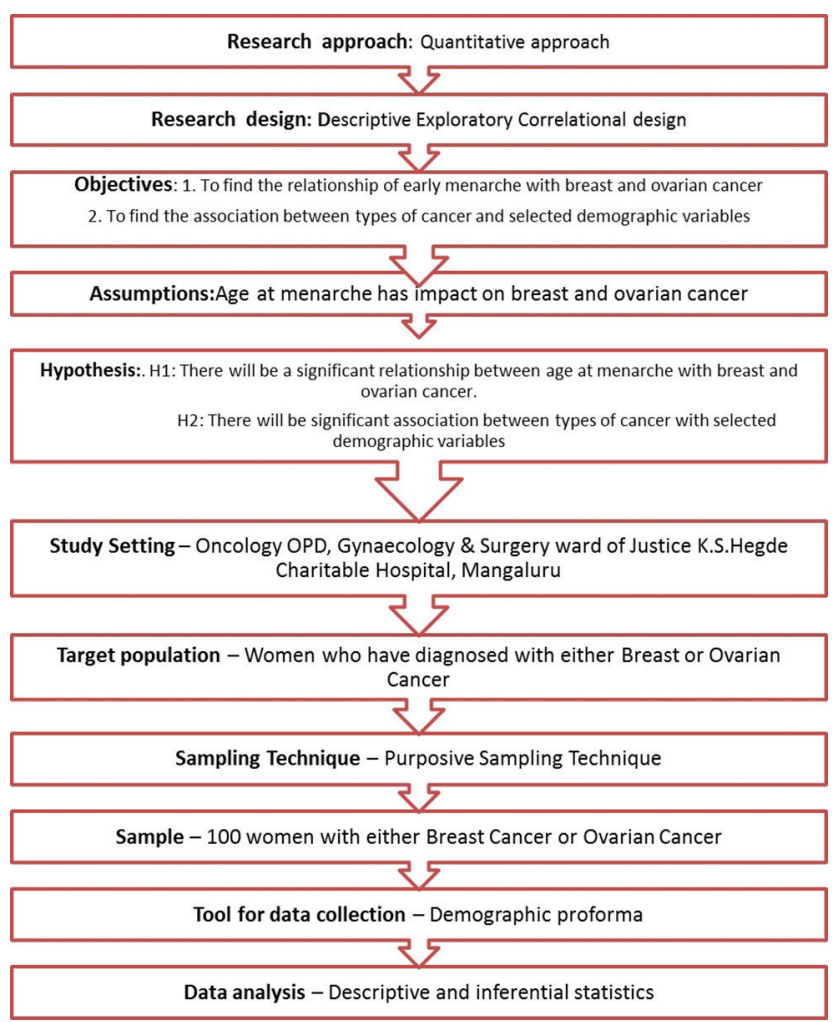

Fig. 1 Schematic representation of research design. early menarche with breast and ovarian cancer among women, who already diagnosed with either breast or ovarian cancer. The setting of the study was in outpatient department and general ward of oncology, gynecology and surgery of Justice K.S Hegde Charitable Hospital Mangaluru. The study population consist of women diagnosed with either breast or ovarian cancer. Purposive sampling technique was used to select 100 women with either breast or ovarian cancer ( - Fig. 1).

\section{Results}

\section{Section 1: Distribution of Demographic Variables of Women with Breast or Ovarian Cancer}

In this study. the majority (36\%) of the women belonged to the age group of 45 to 54 years, 65\% were housewives, and $87 \%$ hailed from the rural locality. The majority (56\%) of the participants experienced their first menarche at less than 13 years, $84 \%$ did not have a family history of breast or ovarian cancer, $63 \%$ were born at the gestational age of 37 weeks, BMI was between 21 and $25 \mathrm{~kg} / \mathrm{m}^{2}$ among $68 \%$, and $62 \%$ of the women were diagnosed with breast cancer. The $p$ value was 0.365 at (> 0.05 ) which was greater than the table value. Hence, there was no significant relationship of age at menarche with breast and ovarian cancer.

There was, however, a significant association between types of cancer and age. The $p$ value was 0.027 at $(p<0.05)$ level of significance ( - Table $\mathbf{1}$ ).

\section{Section 2: Relationship of Early Menarche with Breast and Ovarian Cancer}

To find the relationship of early menarche with breast and ovarian cancer, the following research hypothesis (H1) was formulated:

H1: There will be a significant relationship between age at menarche with breast and ovarian cancer.

To test the research hypothesis (H1), the following null hypothesis (H01) was formulated:

H01: There is no relationship between age at menarche with breast and ovarian cancer.

Hundred women, either with breast or ovarian cancer, were selected from Justice K.S Hegde Charitable Hospital through purposive sampling based on inclusion criteria. Their age at menarche were assessed and tabulated in a master sheet. The data was analyzed in terms of frequency and percentage ( - Tables $\mathbf{2}$ and $\mathbf{3}$ ).

From the above table, it was found that $37 \%$ of the sample afflicted with breast cancer and 19\% of the sample afflicted with ovarian cancer experienced their first menarche at the age of 13 years or less than that; $21 \%$ of those afflicted with breast cancer and $16 \%$ of those afflicted with ovarian cancer women experienced their first menarche between the age 15 to 16 years; and the remaining four breast cancer and three ovarian cancer participants experienced their first menarche above 16 years of age.

This table depicts that the majority (62) of the samples was afflicted with breast cancer, while the rest of the subjects (38) samples had contracted ovarian cancer. The mean 
Table 1 Frequency and percentage distribution of demographic variables of women with breast or ovarian cancer

\begin{tabular}{|c|c|c|c|c|}
\hline Sr No. & \multicolumn{2}{|l|}{ Demographic Variables } & Frequency $(f)$ & Percentage (\%) \\
\hline \multirow[t]{5}{*}{1.} & \multirow[t]{5}{*}{ Age in years } & $25-34$ & 5 & 5.0 \\
\hline & & $35-44$ & 24 & 24.0 \\
\hline & & $45-54$ & 36 & 36.0 \\
\hline & & $55-64$ & 26 & 26.0 \\
\hline & & $>64$ & 9 & 9.0 \\
\hline \multirow[t]{4}{*}{2.} & \multirow[t]{4}{*}{ Occupation } & House wife & 65 & 65.0 \\
\hline & & Govt. employee & 14 & 14.0 \\
\hline & & Private employee & 7 & 7.0 \\
\hline & & Daily wages & 14 & 14.0 \\
\hline \multirow[t]{4}{*}{3.} & \multirow[t]{4}{*}{ Educational status } & $\begin{array}{l}\text { No formal } \\
\text { education }\end{array}$ & 10 & 6 \\
\hline & & Primary education & 23 & 21 \\
\hline & & High school & 18 & 6 \\
\hline & & PUC and above & 11 & 5 \\
\hline \multirow[t]{2}{*}{4.} & \multirow[t]{2}{*}{ Area of residence } & Urban & 13 & 13.0 \\
\hline & & Rural & 87 & 87.0 \\
\hline \multirow[t]{4}{*}{5.} & \multirow[t]{4}{*}{ Age at menarche in years } & $<13$ & 56 & 56.0 \\
\hline & & $13-14$ & 0 & 0 \\
\hline & & $15-16$ & 37 & 37.0 \\
\hline & & $>16$ & 7 & 7.0 \\
\hline \multirow[t]{2}{*}{6.} & \multirow{2}{*}{$\begin{array}{l}\text { Family history of breast cancer or } \\
\text { ovarian cancer }\end{array}$} & Yes & 16 & 16.0 \\
\hline & & No & 84 & 84.0 \\
\hline \multirow[t]{3}{*}{7.} & \multirow[t]{3}{*}{ Gestational age at birth in weeks } & 36 & 9 & 9.0 \\
\hline & & 37 & 63 & 63.0 \\
\hline & & 38 & 9 & 9.0 \\
\hline
\end{tabular}

Table 2 Distribution of sample characteristic according to age at menarche

\begin{tabular}{|l|l|l|l|l|}
\hline \multirow{2}{*}{$\begin{array}{l}\text { Age at } \\
\text { Menarche }\end{array}$} & \multicolumn{2}{|l|}{ Frequency } & \multicolumn{2}{l|}{ Percentage } \\
\cline { 2 - 5 } & $\begin{array}{l}\text { Breast } \\
\text { cancer }\end{array}$ & $\begin{array}{l}\text { Ovarian } \\
\text { cancer }\end{array}$ & $\begin{array}{l}\text { Breast } \\
\text { cancer }\end{array}$ & $\begin{array}{l}\text { Ovarian } \\
\text { cancer }\end{array}$ \\
\hline$<13$ years & 37 & 19 & $37 \%$ & $19 \%$ \\
\hline $14-15$ years & - & - & - & - \\
\hline $15-16$ years & 21 & 16 & $21 \%$ & $16 \%$ \\
\hline$>16$ years & 4 & 3 & $4 \%$ & $3 \%$ \\
\hline$n=100$. & \multicolumn{5}{l}{} \\
\end{tabular}

Table 3 Relationship of early menarche with breast and ovarian cancer is assessed by using independent sample " $t$ " test

\begin{tabular}{|l|l|l|l|l|l|}
\hline $\begin{array}{l}\text { Diagnosis } \\
\text { or types of } \\
\text { cancer }\end{array}$ & $N$ & Mean & $\begin{array}{l}\text { Standard } \\
\text { deviation }\end{array}$ & $t$-value & $p$-value \\
\hline $\begin{array}{l}\text { Breast } \\
\text { cancer }\end{array}$ & 62 & 1.87 & 1.094 & 0.91 & $\begin{array}{l}0.365 \\
\text { NS }\end{array}$ \\
\cline { 1 - 3 } \\
Cancer
\end{tabular}

Abbreviation: NS, not significant.

$n=100$.

$p>0.05$. difference of ovarian cancer was higher than the mean difference of breast cancer. The $p$ value 0.365 is higher than the 0.05 level of significance. Therefore, age at menarche has no relationship with breast and ovarian cancer.

Again, the null hypothesis (H01) is accepted and research hypothesis (H1) is rejected.

The data presented in - Table $\mathbf{4}$ shows there is no association between the types of cancer and demographic variables such as educational status $\left(\chi^{2}\right.$ calculated value $=0.288<\chi^{2}$ table value $\left.=7.82, p>0.05\right)$ and family history of breast or ovarian cancer $\left(\chi^{2}\right.$ calculated value $=0.400<\chi^{2}$ table value $\left.=3.84, p>0.05\right)$.

\section{Discussion}

Breast and ovarian cancer are the major forms of gynecological cancer occurring among females in India. These are the most serious public health problems causing severe suffering and eventually leading to death.

This study was undertaken to find the correlation between early menarche and breast and ovarian cancer among 100 women in a hospital selected in Mangalore. The findings of the study have been discussed with reference to the objectives and hypothesis stated along with the findings of other studies 
Table 4 Association between type of cancer with selected demographic variables by using Chi-square test

\begin{tabular}{|c|c|c|c|c|c|c|}
\hline \multicolumn{3}{|c|}{ Demographic variables } & Breast cancer & Ovarian cancer & $\mathrm{X}^{2}$ (chi-square) & $p$-value \\
\hline \multirow[t]{4}{*}{ Educational status } & \multicolumn{2}{|c|}{$\begin{array}{l}\text { No formal } \\
\text { education }\end{array}$} & 10 & 6 & \multirow[t]{4}{*}{3.800} & \multirow[t]{4}{*}{$\begin{array}{l}0.288 \\
\text { NS }\end{array}$} \\
\hline & \multicolumn{2}{|c|}{$\begin{array}{l}\text { Primary } \\
\text { education }\end{array}$} & 23 & 21 & & \\
\hline & \multicolumn{2}{|c|}{ High school } & 18 & 6 & & \\
\hline & $\begin{array}{l}\text { PUC } \\
\text { above }\end{array}$ & and & 11 & 5 & & \\
\hline Family history & \multirow{2}{*}{\multicolumn{2}{|c|}{ Yes }} & 8 & 8 & 1.164 & 0.400 \\
\hline of breast or & & & & & & \\
\hline Ovarian & \multirow{2}{*}{\multicolumn{2}{|c|}{ No }} & 54 & 30 & & NS \\
\hline Cancer & & & & & & \\
\hline
\end{tabular}

Abbreviation: NS, Not significant.

In the present study, $36 \%$ of the sample was between the age group of 45 to 54 years, $23 \%$ of them acquired primary education, $65 \%$ were housewives, $56 \%$ of the women experienced menarche at the age of $<13$ years, $84 \%$ of the women had no family history of breast or ovarian cancer, the majority ( $87 \%$ ) belonged to the rural locality, $63 \%$ were in 37 weeks of gestational age, $48 \%$ had birth weight between 2.8 to $3.2 \mathrm{~kg}$, and $62 \%$ and $38 \%$ of the sample were diagnosed with breast cancer and ovarian cancer, respectively.

The findings of a similar supportive study were reported in a case control study on breast cancer patients in Saudi Arabia, and the study results show that the majority (59\%) of the sample involved in that study were in the age group of 30 to 70 years. ${ }^{8}$

A similar supportive case control study conducted on women with breast cancer in Saudi Arabia, with 0450 controls and 225 cases, and the results of the study show that the median age at menarche for cases and control was 11.7 and 13.0 years, respectively. ${ }^{9}$

With regard to association, there was a significant association between type of cancer and age of women with breast or ovarian cancer. The calculated $p$ value of age was 0.027 at $(p<0.05)$ level of significance. Hence, the research hypothesis is accepted. The $p$ value was 0.027 at $(p<0.05)$ level of significance.

\section{Conclusion}

The study concluded that there is a significant association between types of cancer and age of participants. Some of the supportive studies have showed that exists a close relationship between early menarche and late menopause with breast and ovarian cancer. A supportive study on a total of 27 observational studies consisting of 22 case-control and five cohort studies were included in the analysis. In a pooled analysis of all studies, a statistically significant inverse association was observed between menarcheal age (for the oldest compared with the youngest category) and ovarian cancer risk (RR 5 0.85; 95\% confidence interval [CI] 5 0.75-0.97). Identified using MEDLINE, EMBASE, and Web of Science. ${ }^{10} \mathrm{~A}$ contradictory study revealed that women with menarcheal age of 10 or 11 years showed a 2.2-fold risk of breast cancer compared with women who had their first menstrual period at age 12 or later. ${ }^{11}$ The nurse should convince the people regarding the importance of screening for breast and ovarian cancer, and motivate them to participate in community screening programs. Health education can be imparted through mass media, that is, television, radio, pamphlets, poster, information booklets, and so on, which can increase awareness of health problems and potential risk factors contributing to breast and ovarian cancer among susceptible groups such as women and adolescent girls.

\section{Conflicts of Interest}

Nil.

\section{References}

1 Çelik A, Acar M, Erkul CM, Gunduz E, Gunduz M. Relationship of breast cancer with ovarian cancer. In A Concise Review of Molecular Pathology of Breast Cancer; 2015

2 Breastcancer.org. Available at: http://www.breastcancer.org/ symptoms/understand_bc/what_is_bc.Accessed October 1, 2019

3 Torre LA, Trabert B, DeSantis CE, et al. Ovarian cancer statistics, 2018. CA Cancer J Clin 2018;68(4):284-296

4 Cancer Statistics. Available at: http://cancerindia.org.in/cancer-statistics/.Accessed October 1, 2019

5 Lakshmi R, Vijayalakshmi S, Raju A, Joy TM. Assessment of various risk factors of breast cancer. Int J Pharm Pharm Sci 2013;5:30

6 Dannhauser A, Van den Berg VL. Prevalence of the known risk factors in women diagnosed with breast cancer at faculty of health sciences department of nutrition and dietetics university of the free state Queen II Hospital, Maseru (Doctoral dissertation, University of the Free State)

7 Bangal VB, Shinde KK, Gavhane SP, Satyajith, Singh RK. Breast carcinoma in women-a rising threat. Int J Biol Adv Res 2013;04(2):74-76

8 Pięta B, Chmaj-Wierzchowska K, Opala T. Past obstetric history and risk of ovarian cancer. Ann Agric Environ Med 2012;19(3):385-388

9 Alghamdi IG, Hussain II, Alghamdi MS, Elsheemy M. Early marriage is a potential risk factor for female breast cancer in the 
80 Relation of Menarche, Breast, and Ovarian Cancer in Women Sunanda and Nayak

eastern region of Saudi Arabia. American Journal of Research Communication 2015;3(7

10 Gong TT, Wu QJ, Vogtmann E, Lin B, Wang YL. Age at menarche and risk of ovarian cancer: a meta-analysis of epidemiological studies. Int J Cancer 2013;132(12):2894-2900
11 Kapil U, Bhadoria AS, Sareen N, Singh P, Dwivedi SN. Reproductive factors and risk of breast cancer: A Review. Indian J Cancer 2014;51(4):571-576 